\title{
Control of diabetes and fibrinogen levels as well as improvement in health care might delay low cognitive performance in societies aging progressively
}

Controle do diabetes e dos níveis de fibrinogênio, bem como melhora no cuidado com a saúde, podem retardar o baixo desempenho cognitivo em sociedades que apresentam envelhecimento progressivo

Daniele Almeida Lopes', Suzana Alves de Moraes², Isabel Cristina Martins de Freitas ${ }^{1}$

\begin{abstract}
Objective: To know the prevalence and factors associated to low cognitive performance in a representative sample of the adult population in a society aging progressively. Method: Cross-sectional population-based study carried out in a three-stage sampling: 81 census tracts (primary sampling unity) were randomly selected, followed by 1,672 households and 2,471 participants (weighted sample) corresponding to the second and third stages, respectively. The outcome prevalence was calculated according sociodemographic, behavioral and health related variables. Crude and adjusted prevalence ratios were estimated using Poisson regression. Results: The prevalence of low cognitive performance was high, mainly among females, and indicated linear trends into categories of age, schooling, income, plasma fibrinogen and self-reported health status. In multivariate models, gender, diabetes, fibrinogen and self-reported health status presented positive associations, while schooling, employment and sitting time presented negative associations with the outcome. Conclusion: Interventions related to diabetes and fibrinogen levels control as well as improvement in health care might delay low cognitive performance in societies aging progressively as such the study population.
\end{abstract}

Keywords: cognitive impairment, adults, associated factors, cross-sectional studies.

RESUMO

Objetivo: Estimar a prevalência e os fatores associados ao baixo desempenho cognitivo em amostra representativa de adultos pertencentes a uma população com envelhecimento progressivo. Método: Estudo transversal, de base populacional, conduzido em amostra selecionada em três estágios: 81 setores censitários (unidade primária de amostragem) foram selecionados aleatoriamente, seguidos por 1.672 domicílios e 2.471 participantes (amostra ponderada), correspondendo ao segundo e terceiro estágios, respectivamente. A prevalência do desfecho foi calculada segundo fatores sociodemográficos, comportamentais e relacionados à saúde. Razões de prevalência brutas e ajustadas foram estimadas pela regressão de Poisson. Resultados: A prevalência de baixo desempenho cognitivo foi elevada, principalmente nas mulheres, indicando gradiente linear em relação à idade, à escolaridade, à renda, aos níveis de fibrinogênio e à saúde autorreferida. Nos modelos multivariados, sexo, diabetes, fibrinogênio e saúde autorreferida apresentaram associações positivas, enquanto escolaridade, trabalho e tempo sentado apresentaram associações negativas com o desfecho. Conclusão: Medidas de controle do diabetes, dos níveis de fibrinogênio plasmático e melhora da atenção à saúde poderão retardar o baixo desempenho cognitivo em sociedades que apresentam envelhecimento progressivo como a população do estudo.

Palavras-chave: desempenho cognitivo, adultos, fatores associados, estudos transversais.

Over the last few decades and as a result of the demographic transition, the relative increase in the number of elderly people in the population has led to a significant increase in the prevalence of chronic diseases ${ }^{1}$. The aging process may be followed by a decline in cognitive performance, with gradual impairment of written and spoken

${ }^{1}$ Núcleo de Epidemiologia (NEPI), Escola de Enfermagem de Ribeirão Preto, Universidade de São Paulo, Ribeirão Preto SP, Brazil;

${ }^{2}$ Departamento de Enfermagem Materno-Infantil e Saúde Pública, Escola de Enfermagem de Ribeirão Preto, Universidade de São Paulo, Ribeirao Preto SP, Brazil.

Correspondence: Suzana Alves de Moraes; Av. Bandeirantes, 3900; 14040-902 Ribeirão Preto SP, Brasil; E-mail: samoraes@usp.br

Conflict of interest: There is no conflict of interest to declare.

Received 21 March 2014; Received in final form 12 September 2014; Accepted 02 October 2014. 
language, learning, motor skills, reasoning and memory capacity ${ }^{2}$.

Impairment of cognitive function is especially characterized by progressive loss of intellectual abilities, such as loss of the capacity for discernment, loss of attention and perception, and loss of visual and spatial skills. Such losses consequently have direct implications for these individuals' lives and may interfere in their day-to-day activities, in maintaining their social relationships and in their professional performance, thereby contributing towards reducing their wellbeing and quality of life ${ }^{3}$.

Different authors have identified associations between low cognitive performance (LCP) and sociodemographic ${ }^{4,5}$, behavioral $^{6,7}$ and health-related factors ${ }^{8,9}$. The influence of age and schooling level on LCP have been consistently observed, as have certain habits such as smoking and alcohol abuse and diseases such as hypertension and diabetes.

In Brazil, studies relating to cognitive performance have been concentrated in state capitals of southern and southeastern regions and have mainly related to the elderly population. Population-based epidemiological studies in municipalities away from the state capitals, with allocation of representative samples of adults, remain scarce. Considering those limitations, the present study aims to know the prevalence and factors associated to low cognitive performance in a representative sample of the adult population living in Ribeirao Preto, state of Sao Paulo, Brazil.

\section{METHOD}

\section{Study design and sampling}

Cross-sectional population-based epidemiological study carried out in Ribeirao Preto, SP, between 2007 and 2008, as part of a larger project named "Prevalence of cardiovascular diseases and identification of associated factors among adults living in Ribeirao Preto, SP" (EPIDCV Project). The sampling process was developed in three stages, and the precision of the estimates was calculated on a sample of 1,205 individuals. The response rate was $82.1 \%$ and, 1,133 individuals of both gender, aged 30 years or over attended. The variability resulting from multiple stages of draws was corrected and gave rise to a weighted sample $(\mathrm{nw})^{10}$ of 2,471 participants. Details of sampling were described in a previous published paper ${ }^{11}$.

\section{Outcome}

Low cognitive performance (LCP). Information on cognitive performance was obtained by applying the Mini-Mental State Examination (MMSE), proposed by Folstein et al. ${ }^{12}$ and validated in Brazil by Bertolluci et al. ${ }^{5}$. For the purpose of the present study, the MMSE scores (range 0 to 30) were classified in two categories, using the $25^{\text {th }}$ percentile, which corresponds in this population to the MMSE score of 25 . Thus, based on that cutoff the participants were classified as low cognitive performance (MMSE scores $\leq 25$ ), and high cognitive performance (MMSE scores $>25$ ).

\section{Variables \\ Sociodemographic}

Gender (both gender); age classified in 10-year intervals; schooling level classified according the number of years of formal education; individual income classified according to tertiles; employment (yes or no); and marital status (defined according to the presence or absence of a partner, independent of whether there was any formal union).

\section{Behavioral}

Years of smoking, corresponding to the total number of years as a smoker (classified according to tertiles); severity levels of alcohol addiction, classified in four categories: (07/no dependence); (8-15/light dependence); (16-19/moderate dependence, and (20-40/severe dependence) according the Alcohol Use Disorder Identification Test (AUDIT) scores $^{13}$, and physical activity pattern (PAP), defined according the median number of units of metabolic waste (Mets* min $^{*}$ week $^{-1}$ ) and daily mean of sitting time tertiles (min/ day) according the International Physical Activity Questionnaire (IPAQ), short version ${ }^{14}$.

\section{Health-related variables}

Diabetes mellitus, defined according to previous history of the condition diagnosed by a physician and also oral glucose tolerance test (OGTT), performed after 12-hour fasting and two hours after an overload of 75 grams of glucose. Glycemia (mg/dL) was measured in capillary blood by means of the reflectance colorimetry method, using the portable Accutrend device (Roche Diagnostics $\mathrm{GmbH}$, Mannheim, Germany), taking the cutoff recommended by $\mathrm{WHO}^{15}$; hypertension, defined according to previous history of the condition diagnosed by a physician, regular use of anti-hypertensive medication or the mean of three consecutive arterial blood pressure measurements. Individuals were considered to be hypertensive if they presented measurements $\geq 140 \times 90 \mathrm{mmHg}$ for systolic and diastolic pressure, respectively ${ }^{16}$; ischemic heart disease (IHD), defined by the combination of angina and possible myocardial infarction, applying the Rose Questionnaire (Q-Rose) $)^{17}$; nutritional status, classified in three categories according to the body mass index (BMI) cutoff(s): eutrophic (BMI: 18.5-24.9); overweight (BMI: 25.0-29.9), and obesity (BMI: $\geq 30$ ) as recommended by $\mathrm{WHO}^{18}$; and plasma fibrinogen and total cholesterol assays (in $\mathrm{mg} / \mathrm{dL}$ ), processed in a reference laboratory, after 12 hours of fasting. Fibrinogen was classified in three categories, according to tertiles. Cholesterolemia was classified in two categories: $<200 \mathrm{mg} / \mathrm{dL}$ and $\geq 200 \mathrm{mg} / \mathrm{dL}$. Central 
nervous system (CNS) medications (antidepressants, anxiolytics, anticonvulsants, antipsychotics, hypnotics and opiates) taken over the 15-day period preceding the interviews were informed by the study participants and also checked by the interviewers based on prescriptions and/or drug-packs. The group classification of CNS medications was based on the Dictionary of Pharmaceutical Specialties (2013), and the variable was classified in two categories (yes or no). Self-reported health status was classified in three categories: "same", "worse" and "better", compared with friends at similar age.

\section{Data processing}

Data were collected by face-to-face interviews at the household of eligible individuals, by a team of interviewers who had been trained previously. Before typing data (double-entry), the quality-control was assessed by replicating $12.5 \%$ of the interviews, using Kappa statistics to assess reliability. The Kappa coefficient was $>0.80$.

\section{Statistical analysis}

The specific prevalence of LCP according to gender and age groups were calculated by points and 95\% confidence intervals. The prevalence of the outcome was also estimated, according to sociodemographic, behavioral and healthrelated variables. Poisson regression ${ }^{19}$ was used to estimate prevalence ratios (PRs). Crude analyses were performed initially, and the variables with $\mathrm{p}$-values $\leq 0.25$ for the Wald statistic were selected for inclusion in the multivariate models. Following this, PRs were calculated separately in three models that, respectively, contained sociodemographic, behavioral and health-related variables. After simultaneously adjusted for, the variables that within each of these groups presented p-values $<0.05$ for Wald statistic were considered independently associated with the outcome. Linear trend tests were run for PRs in variables with more than two categories. All the analyses were run in Stata10. The design effect (deff) was considered (survey commands family).

\section{Ethical issues}

The EPIDCV Project was approved by the Research Ethics Committee of the Ribeirao Preto Nursing School, University of Sao Paulo, under the protocol no. 0725/2006. All the participants signed a free and informed consent statement, in conformity with the recommendations of Resolution no. 196/96 of the National Health Council.

\section{RESULTS}

Table 1 presents the sample characteristics, according to sociodemographic variables. Most participants had high schooling, were inserted in the work market and were living with a partner. Table 2 shows that the prevalence of LCP had a direct relation with age, in both gender, and was of greater magnitude among females. The design effect was 2.53977. In relation to sociodemographic variables (Table 3), it was observed that schooling presented inverse relation with the outcome, and that the prevalence of LCP reached higher magnitude among individuals without a partner and among those who had no employment. Adjusted PRs depicted positive and independent association with LCP for female gender, whereas schooling and employment presented negative associations with the outcome. PRs into categories of schooling showed linear trend $(\mathrm{p}<0.01)$. In relation to behavioral variables (Table 4), higher- magnitude prevalence of LCP was observed among participants with lower metabolic waste, those with lower daily mean of sitting time (min/day), those who achieved higher values for AUDIT scores, and those who had been smokers for longer times. In the adjusted model, only daily mean of sitting time PRs showed an independent and negative effect related to the outcome. In relation to health-related variables (Table 5), higher-magnitude prevalence was observed among participants diagnosed as having diabetes, hypertension and ischemic heart disease, and also among those who presented higher levels of fibrinogen and total cholesterol. Participants using CNS medications presented higher prevalence of LCP, in comparison with those who were not making use of this group of medications. The prevalence of LCP into categories of health status compared to friends suggested linear gradient. Adjusted PRs into this group exhibited a positive and independent effect related to the outcome for diabetes, fibrinogen and self-reported health status. PRs into categories of health status presented linear trend ( $p$-value $<0.01$ ).

\section{DISCUSSION}

The results showed high LCP prevalence, mainly among women, which increased with age, in both gender. Gender, diabetes, fibrinogen and self-reported health status presented positive associations, while schooling, employment and sitting time presented negative associations with the outcome.

The methodological strategies related to sampling, the high response rate $(>80 \%)$, and the quality control of replicated questions (Kappa $>0.80$ ) indicate that the findings do not seem resulting from systematic bias.

The predominance of women in the general population, particularly at more advanced ages, and the consequent accumulation of chronic diseases in females, would be a plausible explanation for these findings. On the other hand, widowhood and solitude, more frequent among women, may lead to depressive conditions that, in themselves, may have a 
Table 1. Demographic characteristics of the study sample. Ribeirao Preto, SP, Brazil, 2007. EPIDCV Project.

\begin{tabular}{|c|c|c|c|}
\hline & $\mathrm{N}_{\mathrm{w}}$ & $\%$ & $95 \% \mathrm{Cl}$ \\
\hline \multicolumn{4}{|l|}{ Gender } \\
\hline Male & 995.70 & 40.30 & $37.21-43.36$ \\
\hline Female & $1,475.00$ & 59.70 & 56.64-62.69 \\
\hline \multicolumn{4}{|l|}{ Age groups } \\
\hline 30-39 years & 661.30 & 26.76 & $23.40-30.42$ \\
\hline 40-49 years & 765.70 & 30.99 & 28.30-33.81 \\
\hline 50-59 years & 507.30 & 20.53 & $18.26-23.00$ \\
\hline$\geq 60$ years & 536.60 & 21.72 & $18.85-24.89$ \\
\hline \multicolumn{4}{|l|}{ Schooling } \\
\hline $0-3$ years & 343.80 & 14.06 & 11.52-17.05 \\
\hline 4-7 years & 739.80 & 30.25 & $26.60-34.16$ \\
\hline $8-11$ years & 821.50 & 33.59 & $30.34-37.00$ \\
\hline$\geq 12$ years & 540.80 & 22.11 & 17.03-28.19 \\
\hline \multicolumn{4}{|l|}{ Individual income (in $\mathrm{R} \$$ ) } \\
\hline No income & 848.90 & 34.35 & $31.60-37.21$ \\
\hline $1^{\text {st }}$ tertile $(\geq 50.00 \leq 700.00)$ & 549.70 & 22.25 & $19.28-25.53$ \\
\hline $2^{\text {nd }}$ tertile $(>700.00 \leq 1,400.00)$ & 506.00 & 20.48 & $17.99-23.20$ \\
\hline $3^{\text {rd }}$ tertile $(>1,400.00)$ & 566.40 & 22.92 & $19.25-27.06$ \\
\hline \multicolumn{4}{|l|}{ Marital status } \\
\hline Without partner & 824.80 & 33.38 & $30.07-36.86$ \\
\hline With partner & $1,646.00$ & 66.62 & 63.14-69.93 \\
\hline \multicolumn{4}{|l|}{ Employment } \\
\hline No & 847.80 & 34.31 & $31.55-37.17$ \\
\hline Yes & $1,623.00$ & 65.69 & $62.83-68.45$ \\
\hline
\end{tabular}

negative influence on cognitive performance. Higher prevalence of LCP among women was also found by Juncos-Rabadan et al. $^{20}$, in a cross-sectional study carried out in Galicia (Spain) among adults $\geq 50$ years.

The influence of age on the prevalence of LCP was evident in the descriptive phase although the association with the outcome have lost statistical significance in multivariate models, mainly after simultaneous adjustment for schooling. Schooling has consistently been described in the literature as strongly associated with cognitive performance $e^{3,4,5,20}$, and these findings were confirmed in the present study. The inverse relationship between educational level and cognitive performance may have resulted from the greater exposure among individuals of lower educational level to environmental factors with adverse effects on the central nervous system, such as poor nutrition, low neuropsychomotor stimulation, and greater exposure to precarious living conditions, particularly during the early years of life, reflected in adulthood as $\mathrm{LCP}^{21}$. Moreover, it is reasonable to suppose that the strongest relationship of schooling with LCP in modeling process could have weakened potential associations of other sociodemographic variables.

In a cross-sectional study using multilevel approach, carried out among communities of elderly people living in Singapore, Wee et al. ${ }^{22}$ found that sociodemographic variables, considered at the individual level (age, gender, educational level and participation in the labor market) or at the ecological level (variables related to poverty degrees) presented significant associations with cognitive performance assessed by MMSE. The effect of participation in the labor market on elderly people's cognitive performance, as

Table 2. Cognitive performance prevalence according age and gender. Ribeirao Preto-SP, Brazil, 2007. EPIDCV Project.

\begin{tabular}{|c|c|c|c|c|}
\hline \multirow{2}{*}{ Age groups } & \multicolumn{2}{|c|}{ Male $\left(n_{w}=995.7\right)^{*}$} & \multicolumn{2}{|c|}{ Female $\left(n_{w}=1,475.0\right)^{*}$} \\
\hline & $>25 \%[95 \% \mathrm{Cl}]$ & $\leq 25 \%[95 \% \mathrm{Cl}]$ & $>25 \%[95 \% \mathrm{Cl}]$ & $\leq 25 \%[95 \% \mathrm{Cl}]$ \\
\hline 30-39 years & 79.85 [72.73-85.48] & 20.15 [14.52-27.27] & $72.43[61.44-81.24]$ & 27.57 [18.76-38.56] \\
\hline 40-49 years & 76.13 [67.03-83.34] & 23.87 [16.66-32.97] & 68.17 [58.74-76.31] & 31.83 [23.69-41.26] \\
\hline 50-59 years & 73.34 [62.14-82.18] & $26.66[17.82-37.86]$ & $64.49[54.79-73.12]$ & 35.51 [26.88-45.21] \\
\hline$\geq 60$ years & 62.93 [50.51-73.85] & 37.07 [26.15-49.49] & $47.30[37.39-57.42]$ & $52.70[42.58-62.61]$ \\
\hline Total & 74.27 [69.07-78.87] & 25.73 [21.13-30.93] & $63.47[57.94-68.66]$ & $36.53[31.34-42.06]$ \\
\hline
\end{tabular}

${ }^{*} n_{w}=$ Weighted sample taking into account the design effect $($ deff $=2.53977)$. 
Table 3. Outcome prevalence, and crude and adjusted prevalence ratios, according sociodemographic variables. Ribeirao Preto, SP, Brazil, 2007. EPIDCV Project.

\begin{tabular}{|c|c|c|c|}
\hline & LCP prevalence $[95 \% \mathrm{Cl}]$ & Crude PR [95\%Cl] & Adjusted PR [95\%Cl] \\
\hline \multicolumn{4}{|l|}{ Gender } \\
\hline Male & 25.73 [21.13-30.93] & 1 & 1 \\
\hline Female & 36.53 [31.34-42.06] & $1.42[1.16-1.72]$ & $1.25[1.04-1.50]$ \\
\hline \multicolumn{4}{|l|}{ Age groups } \\
\hline 30-39 years & 23.80 [18.38-30.23] & 1 & 1 \\
\hline 40-49 years & 28.97 [22.84-35.98] & $1.21[0.92-1.60]$ & $1.04[0.80-1.34]$ \\
\hline $50-59$ years & $32.25[25.47-39.86]$ & $1.35[1.01-1.81]$ & $0.99[0.74-1.32]$ \\
\hline$\geq 60$ years & $47.05[38.50-55.78]$ & $1.97[1.47-2.65]$ & $1.09[0.83-1.45]$ \\
\hline \multicolumn{4}{|l|}{ Schooling } \\
\hline $0-3$ years & 69.87 [61.20-77.32] & 1 & $\mathbf{1}^{\dagger}$ \\
\hline 4-7 years & 39.82 [33.92-46.03] & $0.56[0.47-0.68]$ & $0.60[0.49-0.73]$ \\
\hline $8-11$ years & 20.24 [16.01-25.25] & $0.28[0.22-0.36]$ & $0.32[0.25-0.41]$ \\
\hline$\geq 12$ years & $13.71[10.07-18.40]$ & $0.19[0.14-0.27]$ & $0.22[0.15-0.31]$ \\
\hline \multicolumn{4}{|l|}{ Marital status } \\
\hline Without partner & 36.08 [30.77-41.76] & 1 & 1 \\
\hline With partner & 30.26 [25.44-35.57] & $0.83[0.69-1.01]$ & $0.98[0.83-1.15]$ \\
\hline \multicolumn{4}{|l|}{ Employment } \\
\hline No & 45.62 [38.92-52.49] & 1 & 1 \\
\hline Yes & 25.27 [21.23-29.78] & $0.55[0.46-0.65]$ & $0.82[0.70-0.96]$ \\
\hline
\end{tabular}

LCP: Low cognitive performance; PR: Prevalence ratios; Cl: Confidence interval; ${ }^{\dagger} p$-value $<0.01$ for linear trend test; $p$-value $<0.05$ for PRs are shown in bold.

reported by Wee et al. ${ }^{22}$, was also depicted in the present study, even after adjustment for schooling, thus indicating the strength of this association with regard to adults aged 30 years or over.

In relation to behavioral factors, participants who were classified in the last two tertiles of sitting time presented prevalence ratios $<1$ (protective effect), compared to those at the first tertile. Notwithstanding the benefits of physical exercise for cardiovascular conditioning, thereby favoring cerebral metabolic activity and improving physical and mental health ${ }^{23}$, it is plausible to suppose that participants classified in the higher levels of sitting time may have been engaged in intellectual activities and, in this case, the sedentary lifestyle, expressed through greater sitting time would be an indicator, albeit indirectly, of higher educational level. Higher prevalence of LCP were detected among participants classified as having moderate or severe dependence on alcohol, and among those who had been smokers for longer

Table 4. Outcome prevalence and crude and adjusted prevalence ratios, according behavioral variables. Ribeirao Preto, SP, Brazil, 2007. EPIDCV Project.

\begin{tabular}{|c|c|c|c|}
\hline & LCP prevalence $[95 \% \mathrm{Cl}]$ & Crude PR $[95 \% \mathrm{Cl}]$ & Adjusted PR $[95 \% \mathrm{Cl}]$ \\
\hline \multicolumn{4}{|l|}{ Metabolic waste $\left(\right.$ mets $^{\star} \min ^{\star}$ week $^{-1}$ ) } \\
\hline$\leq 346.50$ & $33.53[28.12-39.42]$ & 1 & 1 \\
\hline$>346.50$ & 30.85 [26.22-35.89] & $0.91[0.76-1.10]$ & $0.89[0.75-1.07]$ \\
\hline \multicolumn{4}{|l|}{ Sitting time (min/day) } \\
\hline $1^{\text {st }}$ tertile $(\leq 180)$ & $38.20[32.10-44.69]$ & 1 & 1 \\
\hline $2^{\text {nd }}$ tertile $(>180 \leq 308.61)$ & $28.42[22.70-34.93]$ & $0.74[0.60-0.91]$ & $0.73[0.59-0.89]$ \\
\hline $3^{\text {rd }}$ tertile $(>380.61)$ & $29.34[24.48-34.72]$ & $0.76[0.62-0.93]$ & $0.75[0.61-0.91]$ \\
\hline \multicolumn{4}{|l|}{ AUDIT (scores) } \\
\hline No dependence (0-7) & $32.72[28.26-37.51]$ & 1 & 1 \\
\hline Light dependence (8-15) & $26.30[19.39-34.60]$ & $0.80[0.60-1.06]$ & $0.80[0.60-1.07]$ \\
\hline Moderate dependence (16-19) & $38.35[23.23-56.11]$ & $1.17[0.73-1.87]$ & $1.20[0.74-1.95]$ \\
\hline Severe dependence (20-40) & $47.33[29.63-65.73]$ & $1.44[0.99-2.10]$ & $1.42[0.97-2.08]$ \\
\hline \multicolumn{4}{|l|}{ Years of smoking } \\
\hline No smoking & $31.45[26.75-36.56]$ & 1 & 1 \\
\hline $1^{\text {st }}$ tertile $(1-13)$ & 35.98 [28.73-43.93] & $1.14[0.90-1.44]$ & $1.14[0.90-1.44]$ \\
\hline $2^{\text {nd }}$ tertile $(14-25)$ & $25.12[18.66-32.91]$ & $0.79[0.60-1.04]$ & $0.77[0.57-1.02]$ \\
\hline $3^{\text {rd }}$ tertile $(>25)$ & $39.23[30.28-48.98]$ & $1.24[0.96-1.60]$ & $1.25[0.96-1.63]$ \\
\hline
\end{tabular}

LCP: Low cognitive performance; PR: Prevalence ratios; Cl: Confidence interval; AUDIT: Alcohol Use Disorder Identification Test; $p$-value < 0.05 for PRs are shown in bold. 
Table 5. Outcome prevalence and crude and adjusted prevalence ratios, according health-related variables. Ribeirao Preto, SP, Brazil, 2007. EPIDCV Project.

\begin{tabular}{|c|c|c|c|}
\hline & LCP prevalence $[95 \% \mathrm{Cl}]$ & Crude PR $[95 \% \mathrm{Cl}]$ & Adjusted PR [95\%Cl] \\
\hline \multicolumn{4}{|l|}{ Diabetes } \\
\hline No & 29.27 [24.80-34.18] & 1 & 1 \\
\hline Yes & $42.39[34.55-50.64]$ & $1.44[1.17-1.79]$ & $1.34[1.07-1.67]$ \\
\hline \multicolumn{4}{|l|}{ Hipertension } \\
\hline No & $30.12[25.55-35.12]$ & 1 & 1 \\
\hline Yes & $35.32[29.60-41.50]$ & $1.17[0.97-1.40]$ & $1.15[0.93-1.41]$ \\
\hline \multicolumn{4}{|l|}{ Ischemic heart disease } \\
\hline No & 31.08 [26.67-35.87] & 1 & 1 \\
\hline Yes & $40.08[31.35-49.50]$ & $1.28[1.01-1.65]$ & $1.10[0.86-1.41]$ \\
\hline \multicolumn{4}{|l|}{ Nutritional status (in $\mathrm{kg} / \mathrm{m}^{2}$ ) } \\
\hline Eutrophic (18.5-24.9) & $33.51[27.46-40.16]$ & 1 & 1 \\
\hline Overweight (25.0-29.9) & 30.57 [25.56-36.09] & $0.91[0.73-1.12]$ & $0.83[0.67-1.04]$ \\
\hline Obesity $(\geq 30)$ & $32.64[27.03-38.80]$ & $0.97[0.78-1.20]$ & $0.81[0.64-1.03]$ \\
\hline \multicolumn{4}{|l|}{ Fibrinogen (in mg/dL) } \\
\hline $1^{\text {st }}$ tertile $(\leq 311.3)$ & 28.23 [22.68-34.53] & 1 & 1 \\
\hline $2^{\text {nd }}$ tertile $(>311.3 \leq 345.3)$ & $29.31[23.37-36.04]$ & $1.03[0.80-1.33]$ & $1.08[0.83-1.40]$ \\
\hline $3^{\text {rd }}$ tertile $(>345.3)$ & $39.44[33.77-45.41]$ & $1.39[1.10-1.76]$ & $1.27[1.00-1.67]$ \\
\hline \multicolumn{4}{|l|}{ Cholesterolemia (in mg/dL) } \\
\hline$<200$ & $29.93[25.55-34.72]$ & 1 & 1 \\
\hline$\geq 200$ & $35.09[29.60-41.01]$ & $1.17[1.00-1.37]$ & $1.07[0.89-1.28]$ \\
\hline \multicolumn{4}{|l|}{ CNS medications } \\
\hline No & $30.92[26.77-35.40]$ & 1 & 1 \\
\hline Yes & $40.13[30.96-50.06]$ & $1.29[1.03-1.63]$ & $1.14[0.86-1.50]$ \\
\hline \multicolumn{4}{|l|}{ Self reported health status } \\
\hline Same (compared to friends) & $26.98[22.32-32.21]$ & 1 & $1^{\dagger}$ \\
\hline Worse (compared to friends) & $34.54[29.01-40.53]$ & $1.28[1.04-1.57]$ & $1.25[1.01-1.54]$ \\
\hline Better (compared to friends) & $47.32[37.13-57.74]$ & $1.75[1.37-2.23]$ & $1.68[1.29-2.19]$ \\
\hline
\end{tabular}

times (descriptive phase), but these variables did not present significant associations with the outcome in the analytical phase and were therefore excluded from the multivariate models. In a cohort of young elderly people (60-64 years of age), Park et al. ${ }^{24}$ observed that the deleterious effect of smoking (direct and dose-response) on cognitive decline was greater among women, while the effect of alcohol was evident among men. However, as shown by Swan et al. ${ }^{25}$ in a recent review, smoking increases oxidative stress and inflammation, thereby contributing towards atherosclerosis, vascular dementia and cognitive decline. On the other hand, it needs to be taken into consideration that possible recall bias related to years of smoking and to the questions included in AUDIT might have led to misclassification bias in these exposures, thus masking the expected results.

In the present study, the multivariate analyses were not stratified by gender, given that the dilution of the sample following stratification led to unstable estimates and loss of statistical power. Moreover, interaction tests between gender and other study variables, in relation to the outcome, did not present statistical significance $(\mathrm{p}>0.05)$.

With regard to health-related variables, diabetes, fibrinogen and self-reported health (compared to friends) remained associated with the outcome. According to Almeida-Pititto et al. ${ }^{26}$, LCP may occur among diabetics due to vascular complications, presence of neurofibrillary plaque in the CNS and changes in glucose metabolism. Lobnig et al. ${ }^{27}$ found that mild CNS atrophy was present in diabetics who had the disease for more than 10 years. The authors suggested that hypoglycemia or hyperglycemia, as well as micro and macrovascular complications, occurring alongside hormonal changes, might explain this finding. Regarding fibrinogen, its main function relates to blood coagulation. Excess of fibrinogen in the intimal layer of the cerebral vessels may lead to thickening and subsequent accumulation of atherosclerotic plaque, and, consequently, impairment of different domains of $\operatorname{cognition}^{28}$. In relation to self-reported health status, the results from multivariate analyses in the present study indicated that there was an independent association with the outcome and a significant linear trend for prevalence ratios ( $p<$ 0.01 ). It is important to mention the plausibility of this association, bearing in mind that because self-reported health is a proxy for comorbidities, its association with the outcome may have resulted from the effect of underlying chronic events.

It needs to be emphasized at this point that cross-sectional studies are susceptible to reverse causality bias resulting from simultaneous assessment of the exposures and the 
outcome. Nonetheless, the associations found in this study do not seem to be resulting from such bias. Another important limitation was the impossibility of evaluating cognitive decline, given the lack of follow-up in studies with this design. Information based on specific questionnaires to evaluate depression or anxiety, well known as related to LCP, was not available in the EPIDCV Project. However, in spite of this limitation it might be plausible to suppose that those conditions were considered, even indirectly, by mean of data related to CNS medications which included antidepressants, anxiolytics, anticonvulsants, antipsychotics, hypnotics and opiates. With regard to the last, the present study confirmed the findings reported by Rollin et al. ${ }^{29}$ in the Health Aging and Body Composition Study cohort (Health $\mathrm{ABC}$ ), in which no association between LCP and CNS medications was found (adjusted hazard ratio $=1.11$; 95\%CI: 0.73-1.69). On the other hand, the effect of hypertension on cognitive decline, which could be observed in cohort studies $^{16}$, was not confirmed in the present study, even so associations between LCP and hypertension or coronary heart disease would be expected. Although higher prevalence of LCP in hypertensive individuals and in those with ischemic heart disease has been found, these variables did not remain in the multivariate models. By the way, contradictory results regarding associations between LCP and cardiovascular diseases were recognized by JuncosRabadan ${ }^{20}$ in cross-sectional studies, and, in a recent cohort, O'Donnell et al. ${ }^{30}$ also did not find any association between LCP and myocardial infarction, although significant associations remained between LCP and stroke.

Most studies carried out in Brazil to investigate LCP prevalence and associated factors included only patients or elderly people, so that direct comparisons of its results with those provided by general population-based designs might be restrictive. Nonetheless those limitations, the present study depicted high LCP prevalence even in those aged under the sixties, suggesting that health promotion and disease prevention should begin in younger.

Ongoing studies within the EPIDCV Project based on multilevel structural equations models will certainly contribute towards better understanding of potential direct, indirect and reciprocal effects between those exposures and cognitive performance.

Despite the limitations, the results based on the present study made it possible to identify the effects of sociodemographic, behavioral and health-related factors on LCP, thus indicating the need for action towards modifiable exposures for which interventions could mitigate the cognitive impairment in a population that is already clearly undergoing to an accelerated process of relative aging.

\section{References}

1. Omran AR. The epidemiologic transition in the Americas. PAHO, Washington: The University of Maryland; 1996.

2. Santos CCC, Pedrosa R, Costa FA, Mendonça KMPP, Holanda GM. Análise da função cognitiva e capacidade funcional em idosos hipertensos. Rev Bras Geriatr Gerontol. 2011;14:241-50.

3. Machado JC, Ribeiro RCL, Cotta RMM, Leal PFG. Declínio cognitivo de idosos e sua associação com fatores epidemiológicos em Viçosa, Minas Gerais. Rev Bras Geriatr Gerontol. 2011;14:109-21.

4. Valle EA, Castro-Costa E, Firmo JOA, Uchoa E, Lima-Costa MF. Estudo de base populacional dos fatores associados ao desempenho no Mini Exame do Estado Mental entre idosos: Projeto Bambuí. Cad Saúde Pública. 2009;25:918-26.

5. Bertolluci PHF, Brucki SMD, Campacci SR, Juliano Y. O Mini-Exame do Estado Mental em uma população geral. Impacto da escolaridade. Arq Neuropsiquiatr. 1994;52:1-7.

6. Nooyens ACJ, Gelder BMV, Verschuren WM. Smoking and cognitive decline among middle-aged men and women: The Doetinchem Cohort Study. Am J Public Health. 2008;98:2244-50.

7. Lobo E, Dufouil C, Marcos G et al. Is there an association between low-to-moderate alcohol consumption and risk of cognitive decline? Am J Epidemiol. 2010;172:708-16.

8. Knopman D, Boland LL, Mosley T et al. Cardiovascular risk factors and cognitive decline in middle-aged adults. Neurology. 2001;56:42-8.

9. Vicario A, Sueldo MD, Fernández RA, Enders J, Zilberman J, Cerezo GH. Cognition and vascular risk factors: an epidemiological study. Int J Hypertens. 2012;2012:783696.
10. Silva NN. Amostragem probabilística: um curso introdutório. 2a ed. São Paulo: Editora da Universidade de São Paulo; 2001.

11. Moraes SA, Freitas ICM. Doença isquêmica do coração e fatores associados em adultos de Ribeirão Preto, SP. Rev Saúde Pública. 2012;46:591-601.

12. Folstein MF, Folstein SE, McHugh PR. Mini-Mental State: a practical method for grading the cognitive state of patients for the clinician. J Psychiatr Res. 1975;12:189-98.

13. Lima CT, Freire ACC, Silva APB, Teixeira RM, Farrel M, Prince M. Concurrent and construct validity of the AUDIT in an urban Brazilian sample. Alcohol \& Alcohol. 2005;40:584-9.

14. Matsudo S, Araujo T, Matsudo V. Questionário Internacional de Atividade Física (IPAQ): estudo de validade e reprodutibilidade no Brasil. Rev Bras Ativ Fis Saúde. 2001;6:5-18.

15. World Health Organization. Report of a WHO Consultation.Definition, diagnosis and classification of diabetes mellitus and its complications. Part 1: diagnosis and classification of diabetes mellitus. Geneva: World Health Organization; 1999. (WHO/NCD/NCS/99.2).

16. Moraes SA, Szklo M, Knopman D, Sato R. The relationship between temporal changes in blood pressure and changes in cognitive function: Atherosclerosis Risk in Communities (ARIC) Study. Prev Med. 2002;35:258-63.

17. Rose GA. The diagnosis of ischaemic heart pain and intermittent claudication in field surveys. Bull. World Health Organ. 1962;27:645-58.

18. World Health Organization. Obesity: preventing and managing the global epidemic: Report of a WHO Consultation. Geneva: World Health Organization; 2000. (WHO technical report series 894). 
19. Barros AJ, Hirakata VN. Alternatives for logistic regression in crosssectional studies: An empirical comparison of models that directly estimate the prevalence ratio. BMC Med Res Methodol. 2003;3:21.

20. Juncos-Rabadan O, Pereiro AX, Facal D, et al. Prevalence and correlates of cognitive impairment in adults with subjective memory complaints in primary care centres. Dement Geriatr Cogn Disord. 2012;33:226-32.

21. Ardila A, Ostrosky-Solis F, Rosselli M, Gómez C. Age-related cognitive decline during normal aging: the complex effect of education. Arch Clin Neuropsychol. 2000;15:495-513.

22. Wee LE, Yeo WX, Yang GR, et al. Individual and area level socioeconomic status and its association with cognitive function and cognitive impairment (Low MMSE) among community-dwelling elderly in Singapore. Dement Geriatr Cogn Disord Extra. 2012;2:529-42.

23. Dustman RE, Ruhling RO, Russell EM, et al. Aerobic exercise training and improved neuropsychological function of older individuals. Neurobiol Aging. 1984;5:35-42.

24. Park B, Park J, Jun JK, Chol KS, Suh M. Gender differences in the association of smoking and drinking with the development of cognitive impairment. PLoS ONE. 2013;8:75095.
25. Swan GE, Lessov-Schlaggar CN. The effects of tobacco smoke and nicotine on cognition and the brain. Neuropsychol Rev. 2007;17:259-73.

26. Almeida-Pititto B, Filho CMA, Cendoroglo MS. Déficit cognitivo: mais uma complicação do diabetes melito? Arq Bras Endocrinol Metab. 2008;52:1076-83.

27. Lobnig BM, Kromeke O, Optenhostert-Porst C, Wolf OT. Hippocampal volume and cognitive performance in longstanding type 1 diabetic patients without macrovascular complications. Diabet Med. 2006;23:32-9

28. Fukujima MM, Martinez TLR, Pinto LESA, Auriemo CRC, Andrade LAF. Fibrinogênio como fator de risco independente de doença vascular cerebral. Arq Neuropsiquiatr. 1997;5:737-40.

29. Wright RM, Roumani YF, Boudreau R, et al. Effect of central nervous system medication use on decline in cognition in communitydwelling older adults: findings from the health, aging and body composition study. J Am Geriatr Soc. 2009;57:243-50.

30. Martin O'Donnell, Koon Teo, Peggy Gao et al. Cognitive impairment and risk of cardiovascular events and mortality. Eur Heart J. 2012;33:1777-86. 